\title{
Earlier sex change in infected individuals of the protogynous reef fish Thalassoma bifasciatum
}

Received: 4 March 2003 / Accepted: 4 September 2003 / Published online: 10 October 2003

(C) Springer-Verlag 2003

\begin{abstract}
Sex allocation theory for sequential hermaphrodites predicts the size at which an individual should change sex, given the different relationships between individual size and reproductive success in the two sexes. We studied a host-parasite system where the myxozoan Kudoa ovivora infects the ovaries of the reef fish Thalassoma bifasciatum, a protogynous sequential hermaphrodite. The parasite sporulates in the host's eggs and renders them infertile. It is thus expected to reduce the female's reproductive success, and could thereby influence host sex change. We present data from marked fish we observed in the field over 4 months. The data suggest that females infected with Kudoa ovivora have a lower reproductive success, change sex earlier and at a smaller size than uninfected females. These results are in agreement with predictions from sex allocation theory, and provide the first example of a possible parasitic influence on the sex allocation of its host.
\end{abstract}

Keywords Sex change $\cdot$ Sequential hermaphrodite $\cdot$ Sex allocation · Size-advantage model · Host-parasite interaction

Communicated by P. Heeb

\footnotetext{
L. Schärer $(\bullet)$

Laboratoire de Parasitologie Evolutive-CNRS UMR 7103, Université Pierre et Marie Curie 7,

Quai Saint Bernard-Case 237, 75252 Paris, Cedex 05, France e-mail: lukas.scharer@uibk.ac.at

Tel.: +43-512-5076170

Fax: +43-512-5072930

D. B. Vizoso

Département de Biologie, Unité d'Ecologie et Evolution, Université de Fribourg,

Chemin du Musée 10, 1700 Fribourg, Switzerland

Present address:

L. Schärer, Institute of Zoology and Limnology, University of Innsbruck,

Technikerstrasse 25, 6020 Innsbruck, Austria
}

\section{Introduction}

Sex allocation theory for sequential hermaphrodites is based on the size-advantage model, which predicts that sex change can occur if the relationships between reproductive success and individual size differ between the sexes. If these relationships are known, the theory can predict in which sex an individual will start life, and at which size it will change sex (Ghiselin 1969; Charnov 1982). Assume a species in which female fitness increases monotonically after the female reaches reproductive maturity, and where females reproduce once per reproductive period. Further imagine that small males are competitively excluded from mating opportunities by larger males, so that small males have low fitness. Once males reach a competitive size their fitness is higher than that of the females because successful males can mate with many females per reproductive period. In such a species, individuals should start life as females and change sex when they reach the size at which they can successfully compete (Ghiselin 1969; Charnov 1982). Such a species would be called a protogynous sequential hermaphrodite (see Fig. 1A for a simplified graphical representation of the argument).

The Caribbean reef fish Thalassoma bifasciatum is one of the best-studied protogynous sequential hermaphrodites, and closely matches the described model for sex change (Fig. 1A). After females mature to size $S_{\mathrm{m}}$, fecundity increases monotonically with size (Warner et al. 1975; Robertson et al. 1999), and females may spawn up to 2 out of 3 days year-round (Schultz and Warner 1991). Large competitive males can spawn up to 100 times per day (Warner 1975) and can therefore attain much higher fitness than females. Females are thus expected to change sex once they reach size $S_{\text {c }}$ (Warner 1988). Both observational and experimental data support this idea (Warner 1975; Warner and Swearer 1991).

Female T. bifasciatum can be infected by an ovarian parasite, the myxozoan Kudoa ovivora, whose transmission stage infects and kills eggs (Swearer and Robertson 1999). In such a system, the parasite is expected to reduce 

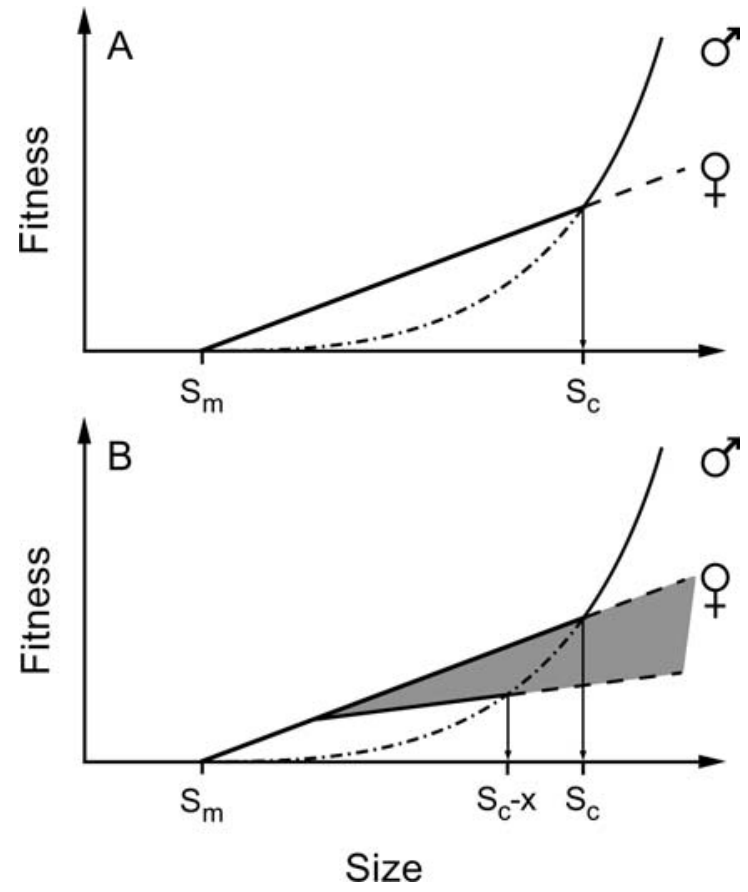

Fig. 1A, B Graphical representation of the size-advantage model for sex change in a protogynous hermaphrodite. A Individuals start their reproductive life as females and mature at size $S_{\mathrm{m}}$. Their fitness increases monotonically until their fitness curve intersects with the male fitness curve at size $S_{\mathrm{c}}$. At this size it pays the female to change sex, and to continue along the male fitness curve rather than along the stippled continuation of the female curve. Males smaller than $S_{\mathrm{c}}$ have a lower fitness than females of the same size (the male curve is stippled there because we do not expect males of that size). B A parasite that reduces the fitness derived by a female from a given reproductive investment will lead to a decrease in the slope of the fitness curve. The fitness that the female loses is indicated by the shaded area. An infected female will intersect the stippled male fitness curve at a smaller size than an uninfected female, and it should therefore change sex at a smaller size (indicated by $S_{\mathrm{c}}-\mathrm{x}$ )

the fitness a female derives from a given reproductive investment, thereby altering the fitness gain curve of the female function (Fig. 1B). We therefore predict that infected females should reach the point where it pays to change sex at a smaller size $S_{\mathrm{c}-\mathrm{x}}$ than uninfected females.

Here we studied the timing of sex change in the above host-parasite system by following infected and uninfected, individually marked females in the field over several months. We checked for differences in sex change between infected and uninfected females, both in terms of the timing and the size at sex change. Further, we estimated the reduction in fitness associated with infection by collecting natural spawns of marked females, and determining egg production and the proportion of eggs that are infected. We further quantified growth and survival in these females to assess potential effects of the parasite on these life-history parameters.

\section{Methods}

The host and the parasite

Fertilization in T. bifasciatum is external and there is no parental care. As fertilization rates are generally high in this species (Marconato et al. 1997), the number of eggs released by a female can serve as a proxy for her current fitness. After a 1-2 month larval period (mean 49 days), fish recruit to a reef and stay there for the rest of their lives (Warner 1975; Warner and Hoffman 1980b; Victor 1986). Individuals start life as either female or male, and display a yellow and brown initial phase (IP) coloration. The brightly colored terminal phase (TP) males derive from IP males that change coloration, or from IP females that change coloration and sex. During the change, fish go through an intermediate (INT) color pattern. The two male morphs exhibit alternative mating strategies: TP males monopolize spawning territories where they pair-spawn with individual females, whereas IP males group-spawn with individual females, or sneak the TP pair-spawns. The ratio of the two male morphs strongly depends on the size of the local population (Warner and Hoffman 1980a). In small populations, such as the one where we performed our study, almost all spawns were with TP males, and IP males were rare or absent.

Female $T$. bifasciatum can be infected with an intracellular parasite, the myxozoan Kudoa ovivora, which invades ovaries and sporulates in eggs (Swearer and Robertson 1999). The spores render infected eggs opaque, so that they can be visually discriminated from uninfected, transparent eggs. The presence of infected eggs is currently the only way of assessing whether a fish carries the parasite. Females that do not produce infected eggs may hence carry the parasite in a phase of its life-cycle where no sporulation occurs. The percentage of infected eggs released by females can vary from zero to $100 \%$ (Swearer and Robertson 1999; personal observation). Vertical transmission is unlikely, because infected eggs fail to develop in vitro. Spores have never been observed in males, suggesting that parasite transmission is sexspecific (Swearer and Robertson 1999).

\section{Study reef}

The study was performed from July to November 2000, on a small reef $(65 \times 40 \mathrm{~m})$ located $1 \mathrm{~km}$ east of Crawl Cay, Bocas del Toro province, Republic of Panama (N 9 14 '48', W 82 $07^{\prime} 47^{\prime \prime}$ '), which is strongly influenced by tidal currents. The reef top frequently emerges from the water at low tide and during wave action, and the reef reaches a depth of approximately $3 \mathrm{~m}$, and is completely surrounded by seagrass beds. The visibility was variable, averaging about $4 \mathrm{~m}$ (range $1-10 \mathrm{~m}$ ). During the study we observed spawns at five different spawning sites.

\section{General methods}

Fish were collected with a lift-net that was baited with sea urchins, or with a large, weighted nylon-net. For measurements, fish were taken to the field station and anesthetized in a 1:30,000 dilution of clove oil (Sigma C-8392) in seawater. We determined the phase (IP, INT, TP), the sex, the standard length (to the nearest millimeter), and the weight (to the nearest $10 \mathrm{mg}$ ). Weight was determined several hours after capture in order to allow fish to empty their guts. We further stripped eggs from females in order to determine clutch size and infection state. We marked fish by injecting visible implant elastomer (Northwest Marine Technology) under the skin (Frederick 1997; Malone et al. 1999). We used three tag locations dorsal of the lateral line using four different colors (red, green, yellow and orange). Each fish was further marked with a red tag to help distinguish between the orange and the red tags in the field, and fish were tagged on both sides to reduce the risk of tag loss. 
Table 1 The number of Thalassoma bifasciatum captured, marked, recaptured, and not recaptured in the four collections. The number of individuals in the different color phases and sexes in the respective collections is given in brackets (TP, INT, IP male, IP female). Note that phase and sex changes occurred during the study period, so that numbers of fish in the different phases and sexes may vary between the collections

\begin{tabular}{|c|c|c|c|c|}
\hline & \multicolumn{4}{|l|}{ Collections } \\
\hline & $\begin{array}{l}\text { Collection } 1 \\
\text { (16-21 July) }\end{array}$ & $\begin{array}{l}\text { Collection } 2 \\
\text { (1-3 Aug) }\end{array}$ & $\begin{array}{l}\text { Collection } 3 \\
\text { (26-27 Aug) }\end{array}$ & $\begin{array}{l}\text { Collection } 4 \\
\text { (22-23 Nov) }\end{array}$ \\
\hline Captured & $\begin{array}{l}62 \\
(11,3,4,44)\end{array}$ & $\begin{array}{l}54 \\
(4,2,5,43)\end{array}$ & $\begin{array}{l}44 \\
(12,1,6,25)\end{array}$ & $\begin{array}{l}28 \\
(4,5,6,13)\end{array}$ \\
\hline Marked & $\begin{array}{l}62 \\
(11,3,4,44)\end{array}$ & $\begin{array}{l}8 \\
(0,0,2,6)\end{array}$ & $\stackrel{3}{\left(2,0,0,1^{\mathrm{a}}\right)}$ & $\begin{array}{c}0 \\
-\end{array}$ \\
\hline Recaptured & - & $\begin{array}{l}46 \\
(4,2,3,37)\end{array}$ & $\begin{array}{l}41 \\
(10,1,6,24)\end{array}$ & $\begin{array}{l}28 \\
(4,5,6,13)\end{array}$ \\
\hline Not recaptured & $\begin{array}{l}- \\
-\end{array}$ & $\begin{array}{l}14 \\
(8,1,1,4)\end{array}$ & $\begin{array}{l}20 \\
(2,3,0,15)\end{array}$ & $\begin{array}{l}36 \\
(12,3,4,17)\end{array}$ \\
\hline Lost & $\begin{array}{l}2 \\
(0,0,0,2)\end{array}$ & $\stackrel{7}{(1,0,0,6)}$ & $\begin{array}{l}0 \\
-\end{array}$ & $\begin{array}{c}0 \\
-\end{array}$ \\
\hline Marked fish on reef & $\begin{array}{l}60 \\
(11,3,4,42)\end{array}$ & $\begin{array}{l}61 \\
(11,3,6,41)\end{array}$ & $\begin{array}{l}64 \\
(14,4,6,40)\end{array}$ & $\begin{array}{l}- \\
-\end{array}$ \\
\hline
\end{tabular}

${ }^{a}$ Not included in study
Fish collections

The number of $T$. bifasciatum captured, marked, recaptured, and not recaptured in the four collections can be seen in (Table 1).

Collection 1: We caught a total of 62 fish over 6 consecutive days, and performed the standard measurements and the marking. After the collection, we systematically swam over the reef and estimated that 10 to 15 fish remained, suggesting a population of about 75 fish. This density of only 0.03 fish $\mathrm{m}^{-2}$ is one order of magnitude lower than the values reported from the well-studied San Blas area in Panama (e.g. Warner and Hoffman 1980a). We released the fish the day after capture, unless otherwise stated.

Collection 2: We caught a total of 54 fish. In addition to the standard measurements, we marked some fish not previously captured. Fish were released on the mornings of 4 and 5 August respectively.

Collection 3: We collected 44 fish, performed the standard measurements, and re-marked some fish whose marks had become difficult to read.

Collection 4: Finally, we recaptured 28 fish and performed the standard measurements.

\section{Field data collection}

We spent approximately 1,000 man-hours on the reef on 84 of the 104 days of the study duration (1 August to 20 November). Spawning occurred from as early as 1000 hours to as late as 1745 hours, and generally lasted for about $1.5 \mathrm{~h}$, but could be spread over $6 \mathrm{~h}$. Most sampling was done on the main spawning site, both because that site was more productive and easier to sample when the sea was rough. Eggs were collected with a custom-made net (a 30 -cm-diameter stainless steel ring fitted with a handle and a conical nylon netting of $250 \mu \mathrm{m}$ mesh size). At the tip of the net we fitted a modified centrifuge tube with a floor of the same netting. When a spawn occurred, we swept the net through the body of water in which the eggs had been released, collecting the eggs in the collection tube. Furthermore, we noted the tags and the estimated size of the female, the time of the day, and other observations. For egg counting, we emptied a sample into a petri dish, and estimated the number of eggs and the proportion of infected eggs. To check if we collected eggs not released by the target females, we collected blank samples. The median number of eggs in such samples was 1 (range 0-54, mean 9.1, $n=47$ ), and none contained infected eggs. However, eggs in blank samples probably stem from other wrasses or parrotfishes that spawn at the same time, some of which were heavily infected. We therefore ignored infected eggs in spawns of females that produced fewer than three infected spawns over the study period (unless a female was found infected from a stripped clutch). This was the case for only four spawns by three females, and each spawn contained only one infected egg. Moreover, to avoid biasing our data due to poorly collected spawns, we excluded the egg counts from spawns with fewer than ten eggs (6\% of all spawns collected).

\section{Life-history parameters}

We restricted the analyses to females from which we had collected a substantial amount of information (i.e. fish that changed sex or that produced eggs at least four times during the study period). The final sample size was 35 females.

\section{Survival}

Every few days we swam over the reef to confirm the presence or absence of the fish. We checked if survival differed between infected and uninfected fish using the proportional hazards platform of JMP 4.0, with number of days from the second collection to the day we last observed a fish on the reef as the survival time. Fish that survived to the end of the study were included as censored in the analysis.

\section{Size and growth}

The four collections yielded an average of 3.1 (range 2-4) weight measurements per fish. Growth rate was estimated as the slope of a linear regression with weight as the dependent variable and day as the independent variable. This yielded an intercept (weight at the start of the study, from hereon "initial size"), and a slope (a measure of growth) for each fish. To check if infected and uninfected fish differed in their growth rate, we calculated an ANCOVA with infection state as the factor, initial size as the covariate, and growth rate as the dependent variable.

\section{Sex change}

We checked for differences in the time of sex change between infected and uninfected females with a proportional hazards analysis as above. As the event time we used the number of days from 1 August to the day we first observed an indication of sex change (i.e. the time until a fish started becoming male). We considered the appearance of blue coloration on the head, the performance of male courtship behavior, or the appearance of a male genital papilla as evidence for sex change. Fish that had not shown signs of sex 
change until they died or until the final collection were included as censored in the analysis. As the size of a fish is expected to influence the timing of sex change, we used it as a covariate in the analysis. Finally, we examined if the estimated size at sex change differed between the infected and uninfected females.

\section{Egg production}

There are several ways in which infection with $K$. ovivora could affect the fitness of its host. First, because they are infertile, the percentage of infected eggs released by a fish over the sampling period can serve as a direct measure of fitness reduction. Second, infected and uninfected females may exhibit a different spawning frequency. As time of sex change is expected to differ between infected and uninfected fish we first had to check if our sampling effort was distributed evenly over the study period. We divided the study period into four periods of 26 days, and found that the fraction of days on which we sampled was not different between the periods (Likelihood-Ratio Test, $\chi^{2}=1.68, d f=3$, $P=0.46$ ). We can thus compare spawning frequencies of fish that changed sex at different times. Spawning frequencies were calculated as the number of spawns in the sampling period corrected for the number of days a fish could have spawned during that time. Finally, infected and uninfected females may differ in the amount of eggs released per spawn. We therefore compared the mean number of uninfected eggs released by the fish (corrected for the size of the fish on the given day). Means were calculated on cube-root transformed values and compared with a $t$-test.

Statistical analysis

We graphically checked if data fulfilled the assumptions of parametric statistics, and transformed if necessary. If no suitable transformation could be found we used nonparametric statistics. For all tests we give two-tailed error probabilities. Averages are given as mean \pm standard error. Data were analyzed with JMP 3.2.2. or JMP 4.0. (Sall and Lehman 1996; SAS Institute Inc. 2000).

\section{Results}

Fish collections

In Table 2 we summarize the number of females we stripped eggs from in each collection, and the number of females that produced infected eggs. We also give an estimate of the prevalence of infection on the reef based on these samples (this value is for the cohort of marked fish we followed, and did not include fish that became reproductive during our study). At the end of study, we were able to collect all of the marked IP fish that had survived.

\section{Collection of natural spawns}

During the study we observed a total of 729 spawns at the five spawning sites ( $n=655,48,11,9$, and 6 respectively). Nine additional spawns were inferred from having seen a female with a distended belly and soon after with a flat belly. We collected at least 10 eggs in 607 spawns, which on average contained 1,135 \pm 48 eggs (median 790, range 10-7,228). For 24 females we had both egg counts from stripped samples and field samples. The mean number of eggs in stripped samples was not significantly higher than the mean number in samples collected in the field (paired $t$-test, $\left.t_{30}=3.12, P=0.19\right)$. We therefore feel confident that our field collections were useful estimates of the number of eggs released by the females. Of the spawns, 57 carried infected eggs ( $9.4 \%$ of spawns), containing an average of $16.1 \%$ infected eggs (median 2.3\%, range 0.02-97.6\%). Of the 35 females we followed, 12 were found to be infected, one based on field samples only, two based on stripped samples only, and nine based on both field and stripped samples. Infected fish spawned primarily at the main spawning site.

\section{Life-history parameters}

\section{Survival}

Thirteen of the 35 females died over the course of the study (6 infected) and 22 survived (6 infected). We found no evidence that infected fish had an increased mortality (Likelihood Ratio Test, $\chi^{2}=1.31, d f=1, P=0.25$ ).

\section{Size and growth}

There was no indication that fish of different infection state differed in weight (infected: $5.28 \pm 0.76 \mathrm{~g}$; uninfected: $5.19 \pm 0.46 \mathrm{~g}, t$-test on cube-root transformed values, $\left.t_{33}=-0.042, P=0.97\right)$. We further found neither a difference in the growth rate between infected and uninfected fish, nor a significant effect of their initial size (ANCOVA, infection state, $F_{1,32}=0.003, P=0.96$; initial size, $F_{1,32}=1.0, P=0.32$, interaction removed from model because it was not significant).
Table 2 The number of female $T$. bifasciatum in the different collections, the number of females with eggs, the number of infected females, and the resulting parasite prevalence of the cohort

\begin{tabular}{|c|c|c|c|c|}
\hline & \multicolumn{4}{|l|}{ Collections } \\
\hline & $\begin{array}{l}\text { Collection } 1 \\
\text { (16-21 July) }\end{array}$ & $\begin{array}{l}\text { Collection } 2 \\
\text { (1-3 Aug) }\end{array}$ & $\begin{array}{l}\text { Collection } 3 \\
\text { (26-27Aug) }\end{array}$ & $\begin{array}{l}\text { Collection } 4 \\
\text { (22-23Nov) }\end{array}$ \\
\hline Captured & 44 & 43 & 25 & 13 \\
\hline Eggs & 7 & 35 & 20 & 9 \\
\hline Infected & 0 & 10 & 4 & 2 \\
\hline Prevalence $(\%)$ & - & 28.6 & 20.0 & 22.2 \\
\hline
\end{tabular}




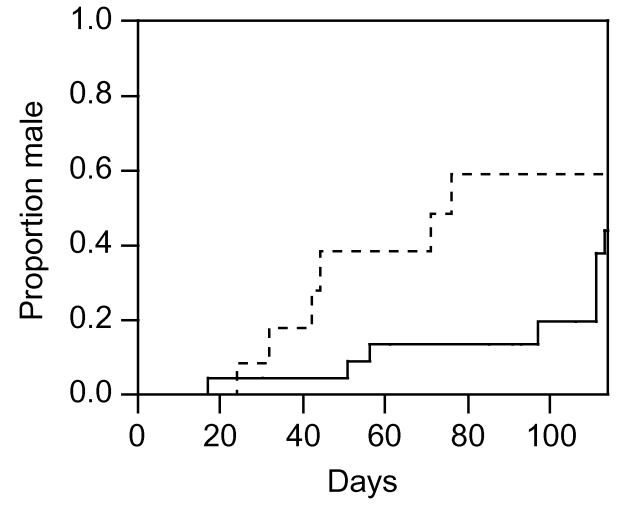

Fig. 2 Differences in the timing of sex change between infected and uninfected female Thalassoma bifasciatum, as assessed by the day of first indication of maleness of 35 fish that were followed in the field over 4 months. The graphs represent event time curves for infected (stippled line) and uninfected (solid line) females

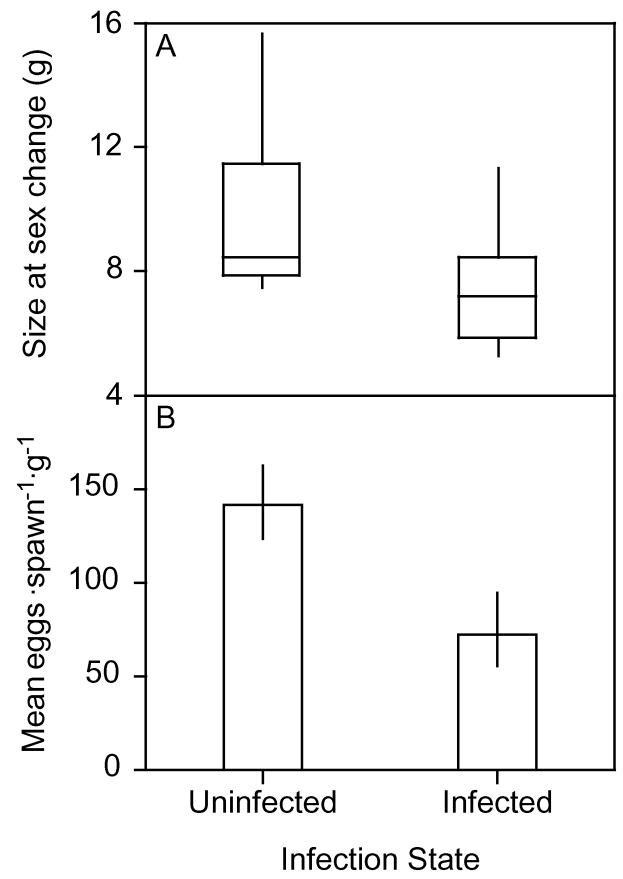

Fig. 3 A The estimated size at sex change of uninfected and infected female T. bifasciatum. The box plots give the medians and the upper and lower quartiles, and the whiskers the range of the distribution. B The mean number of uninfected eggs released per spawn by uninfected and infected female T. bifasciatum (values are corrected for the estimated bodyweight of the fish on the given day). Values were calculated back to the original scale for graphing

\section{Sex change}

Fourteen of the 35 females changed sex during the study (6 infected). As expected, infected females showed signs of having changed sex earlier than uninfected ones (Likelihood Ratio Test, infection state: $\chi^{2}=4.60, d f=1$, $P=0.032, n=35,21$ censored). Furthermore, females that were large at the start of the study changed sex earlier, as expected under the size-advantage model (initial size: $\left.\chi^{2}=9.09, d f=1, P=0.003\right)$. To visualize the earlier sex change in infected fish we plot the event time curves without controlling for the covariate (Fig. 2). Parasiteinduced sex change was further supported by the significantly smaller size at sex change of the infected fish (Exact Wilcoxon Test, Siegel and Castellan 1988, $P=0.02$, $n=14$, Fig. 3A).

\section{Egg production}

In infected fish an average of $2.8 \pm 1.7 \%$ of the eggs released were infected with $K$. ovivora (median $0.8 \%$, range $0.15-17.5 \%, n=10$ ), suggesting a fairly mild fitness reduction for most individuals based on this parameter alone. Furthermore, there was no significant difference between the mean spawning frequencies of infected and uninfected fish (infected, 0.30 \pm 0.04 , uninfected, $0.27 \pm 0.03, t$-Test, $t_{33}=-0.72, P=0.48$ ). However, the number of eggs released per spawn showed a strong difference, with infected females releasing about half the number of eggs per spawn and body weight than uninfected females (untransformed means, infected, $123 \pm 32$ eggs g$^{-1}$, uninfected, $208 \pm 26$ eggs g $^{-1}$, $t$-test on transformed data, $t_{31}=2.46, P=0.019$ ).

\section{Discussion}

Earlier sex change in infected fish

The possibility that a parasite could influence sex change has been previously discussed (Warner 1988), and to our knowledge our study provides the first example. The data we present suggest that female $T$. bifasciatum infected with the myxozoan parasite, $K$. ovivora, change sex earlier. This suggestion is supported by differences in both the timing of, and the size at sex change between uninfected and infected fish. As outlined in the introduction, earlier sex change is expected if the fitness of the female function is reduced by the parasite and if infected fish can change sex to become functional males (see also Swearer and Robertson 1999). Regarding the latter, our data suggest that infected fish can become males, but it remains to be shown how successful they will be. Regarding the female fitness reduction, our data show that infected females released about half the amount of eggs per spawn than uninfected females. It appears that an infected ovary is less efficient at producing eggs or that infected fish have a lower reproductive effort. Our results further suggest a direct fitness loss due to the dispersal stage of the parasite and the subsequent death of infected eggs, although this represents a modest fitness reduction (about 3\%).

Infected females could also lose fitness due to a reduced spawning frequency. The way we calculated the spawning frequency assumed that all fish were equally likely to be seen spawning on the days we sampled, and that no fish were inadvertently sampled more often. As 
stated earlier most infected fish spawned at the main spawning site, on which we sampled more often, and it is therefore conceivable that we collected spawns of infected fish more often. However, this bias would, if present, lead to an overestimation of the spawning frequency of infected fish. Given our results it seems safe to conclude that the spawning frequency of infected fish was not significantly higher than that of uninfected fish. A further fitness loss could stem from an increased mortality in the infected females. But the survival analysis did not suggest this.

\section{Alternative hypotheses}

It is conceivable that sex change depends on the age of a fish. If infected fish were older than uninfected ones, the observed difference might be due to an age difference. As we found no significant difference in initial size between infected and uninfected fish, this would require that the two groups have different growth rates. During our observation period, there was, however, no indication that growth differed between infected and uninfected fish.

A simple, and plausible, alternative hypothesis for the significant reduction in egg production in infected fish could be that the parasite infects low-quality fish, i.e. that the observed difference has nothing to do with the infection itself, but that such low-quality fish die earlier and produce fewer eggs irrespective of whether they are infected or not. A further possibility is that all fish carry the parasite, but that sporulation only occurs in lowquality fish. However, apart from the aforementioned differences in egg production and timing of sex change, there were no obvious phenotypic differences between infected and uninfected fish. To reveal the true causalities it would be necessary to experimentally infect fish with the parasite.

\section{Host-parasite interaction}

This host-parasite system may be interesting for at least one other field of evolutionary biology. Models for the evolution of parasite virulence often define virulence as the fitness reduction of the host (e.g. Frank 1996), a trait that is notoriously difficult to measure. Here, the direct effect of the parasite on fecundity means that parasite virulence can be estimated non-invasively in the field. Furthermore, whereas in most host-parasite systems host death is neither in the interest of the host or the parasite (unless the parasite gets transmission by it), here sex change can be viewed as "host death" from the point of view of the parasite. Sex change leads to the "death" of the tissue in which the parasite sporulates, potentially leading to conflicts of interest between host and parasite over sex change. The earlier sex change in infected fish we find here suggests that the fish retains control over sex change.

\section{Conclusions}

In conclusion, our results are in agreement with the simple graphical sex allocation model we presented in the introduction. They suggest a possible influence of a sexspecific parasite on the timing of sex change of its sequential hermaphrodite host. As infection is a factor that could potentially be experimentally manipulated on an individual basis, this parasite would represent an unmatched experimental tool to test the basic predictions of the size-advantage model. We hope to stimulate parasitological work to uncover the life-cycles of this and other marine myxozoa (e.g. Moran et al. 1999a, 1999b).

Acknowledgements We thank Todd Catalini, Arturo Dominici, Trimurti Irzan, Caroline Joris, Kuno von Wattenwyl, and Jono Wilson for excellent field assistance, and the Smith family for their hospitality at Crawl Cay. Furthermore, we would like to thank the staff of the Smithsonian Tropical Research Institute for invaluable support, particularly Harry Barnes and Luis Mou Sue for support in Bocas del Toro, and John Christy, Arturo Dominici, Allen Herre, Bailey Kessing, Harilaos Lessios and Ross Robertson for support in Panama City. This project profited greatly from discussions with Jacob Koella, Nico Michiels, Steve Swearer, and the participants of the 1998 Population Biology Seminar in Guarda, particularly Mette Hansen. We also thank Anders Berglund, Jacob Koella, Nico Michiels, and Steve Swearer for helpful comments on the manuscript. During this study L.S. was supported by a poste rouge (CNRS, France), an IHP fellowship (SNF, Switzerland), and research funds from the Novartis Foundation, the Janggen-PöhnStiftung, and the Kommission für Reisestipendien of the Swiss Academy of Natural Sciences. D.B.V. was supported by CONICIT (Venezuela). The research was carried out in accordance to Panamanian law.

\section{References}

Charnov EL (1982) The theory of sex allocation, vol 18. Princeton University Press, Princeton, NJ

Frank SA (1996) Models of parasite virulence. Q Rev Biol 71:37_ 78

Frederick JL (1997) Evaluation of fluorescent elastomer injection as a method for marking small fish. Bull Mar Sci 61:399-408

Ghiselin MT (1969) The evolution of hermaphroditism among animals. Q Rev Biol 44:189-208

Malone JC, Forrester GE, Steele MA (1999) Effects of subcutaneous microtags on the growth, survival, and vulnerability to predation of small reef fishes. J Exp Mar Biol Ecol 237:243253

Marconato A, Shapiro DY, Petersen CW, Warner RR, Yoshikawa T (1997) Methodological analysis of fertilization rate in the bluehead wrasse Thalassoma bifasciatum: pair versus group spawns. Mar Ecol Prog Ser 161:61-70

Moran JDW, Whitaker DJ, Kent ML (1999a) Natural and laboratory transmission of the marine myxozoan parasite Kudoa thyrsites to Atlantic salmon. J Aquat Anim Health 11:110-115

Moran JDW, Whitaker DJ, Kent ML (1999b) A review of the myxosporean genus Kudoa Meglitsch, 1947, and its impact on the international aquaculture industry and commercial fisheries. Aquaculture 172:163-196

Robertson DR, Swearer SE, Kaufmann K, Brothers EB (1999) Settlement vs. environmental dynamics in a pelagic-spawning reef fish at Caribbean Panama. Ecol Monogr 69:195 
Sall J, Lehman A (1996) JMP start statistics: a guide to statistical and data analysis using JMP and JMPIN software. Duxbury, Belmont

SAS Institute Inc. (2000) JMP statistics and graphics guide, version 4. SAS Institute, Cary, NC

Schultz ET, Warner RR (1991) Phenotypic plasticity in life-history traits of female Thalassoma bifasciatum (Pisces: Labridae). 2. Correlation of fecundity and growth rate in comparative studies. Environ Biol Fish 30:333-344

Siegel S, Castellan NJ (1988) Nonparametric statistics for the behavioral sciences, 2nd edn. McGraw-Hill, New York

Swearer SE, Robertson DR (1999) Life history, pathology, and description of Kudoa ovivora n. sp. (Myxozoa, Myxosporea): an ovarian parasite of Caribbean labroid fishes. J Parasitol 85:337-353

Victor BC (1986) Duration of the planktonic larval stage of one hundred species of Pacific and Atlantic wrasses. Mar Biol 90:317-326
Warner RR (1975) The adaptive significance of sequential hermaphroditism in animals. Am Nat 109:61-82

Warner RR (1988) Sex change and the size-advantage model. Trends Ecol Evol 3:133-136

Warner RR, Hoffman SG (1980a) Local population size as a determinant of mating system and sexual composition in two tropical marine fishes (Thalassoma spp.). Evolution 34:508518

Warner RR, Hoffman SG (1980b) Population density and the economics of territorial defense in a coral reef fish. Ecology $61: 772-780$

Warner RR, Swearer SE (1991) Social control of sex change in the bluehead wrasse, Thalassoma bifasciatum (Pisces: Labridae). Bioll Bull 181:199-204

Warner RR, Robertson DR, Leigh EG Jr (1975) Sex change and sexual selection. Science 190:633-638 